Bangladesh J. Sci. Ind. Res. 41(3-4), 189-202, 2006

\title{
Study of Water Hyacinth of Bangladesh IV \\ Comparative Study of Pollen Grains and Development of Seed in Both Long and Short Petioled Forms of Eichhornia crassipes (Mart.) Solms-Laubach
}

\author{
Rahima Khatun, ${ }^{a}$ A. S. Islam ${ }^{\mathrm{b}}$ and F. Z. Majid ${ }^{\mathrm{a}}$ \\ ${ }^{a}$ Biological Research Division, BCSIR Laboratories, Dhaka and \\ ${ }^{b}$ Department of Botany, University of Dhaka, Bangladesh.
}

\begin{abstract}
Pollen stainability was found to be more or less similar in long petioled form (LPs) and short petioled form (SPs) of water hyacinth but the size of both oval and round pollen grains was bigger in SPs in comparison to the LPs, the difference being statistically significant. In seed development, significant differences were observed between LPs and SPs at $1 \%$ level only in respect of their average number of capsules and seeds in case of natural pollination. However, in case of artificial self and crosspollinated flowers, significant differences were observed between LPs and SPs at $1 \%$ level in respect of their average number of capsules, seed-bearing capsules and also number of seeds per capsule.
\end{abstract}

\section{Introduction}

Eichhornia crassipes (Mart.) Solms- water hyacinth have been reported to remain Laubach, popularly known as water hyacinth, dormant upto 20 years. ${ }^{4}$ But in Malaysia fruit is a floating hydrophyte, belonging to the monocot family Pontedericeae. Although it is native to Brazil of tropical America, it spread over many tropical and subtropical regions including Bangladesh. Water hyacinth spreads very rapidly, mainly by vegetative means. According to Barrett in growing season 25 plants can produce enough biomass to cover 10,000 square meters of water surface with approximately two million plants. ${ }^{1}$ In certain parts of the world, water hyacinth propagates by seeds also. ${ }^{2,3}$ The seeds of was never reported to be produced. ${ }^{5}$ Bock reported the absence of sexual reproduction in California. ${ }^{6}$ TagEl Seed and Obeid reported that very few capsules set seed in the Nile. ${ }^{3}$ Aghakar and Banerjee reported that bagging the flowers produced fruits indicating that self-pollination occurs to a considerable extent. ${ }^{7}$ Although water hyacinth flowers are attractive and well suited for insect pollination, yet only $35 \%$ of the flowers are pollinated under natural conditions. On the basis of the above observation a comparative 
study was undertaken to study the characteristics of pollen grain and development of seed in both long petioled form (LPs) and short petioled form (SPs) of water hyacinth.

\section{Materials and Methods}

For comparative study of pollen characteristics and seed development, samples of water hyacinth (LPs and SPs) were collected from ditches. After collection, the samples were separated on the basis of petioles. The LPs were characterized by long slender petioles while SPs by short swollen petioles. Selected samples having distinct petiole differences, were then grown separately in earthen tubs, containing tap water.

All experiments were conducted in BCSIR Laboratories, Dhaka.

Pollen grain study

Pollen grain characteristics

After flowering, pollens of both LPs and SPs were collected and stained with acetocarmine and glycerine in the ratio of 1:1 (According to trial and error method). The estimates were based on the examination of 1500 pollen grains. Only well inflated, uniformly stained grains were considered for the study.

The freshly opened anthers were placed in a drop of the stain on a clean slide; anthers were gently squeezed with a pair of forceps and the debris was removed. Cover slip was placed and stainability was scored with a compound microscope. The stainability was expressed in percentage.

Photomicrographs of pollen grains of both LPs and SPs were taken.

Pollen grains were measured using Ocular micrometer (8X45). For this study only fully stained pollen grains were counted for both LPs and SPs.

\section{Development of seed of LPs and SPs}

Development of seed by natural pollination

Water hyacinth flowers are attractive and usually insects visit the flowers, but only $35 \%$ flowers are pollinated under natural condition. After 18 days, the mature capsules were collected and sun-dried. Number of capsules per inflorescence, number of seedbearing capsules per inflorescence, number of seeds per capsule were recorded. Insects visiting the flowers were also recorded.

Use of bagging method for seed development by self or cross-pollination

\section{Development of seeds by self-pollination}

Early in the morning pollen grains from the freshly opened flowers were transferred to the stigma of the same flower with the help of sterilized forceps. The flowers were then covered with a mosquito-net and marked by a tag. After about 18 days the capsules matured. The net was then removed from the inflorescence and the capsules were collected 
and dried under the sun. The dry capsules were dissected to detect the presence or absence of seed in them. If seeds were present, their number was determined. Record was maintained of the number of capsules per inflorescence, number of seed-bearing capsules per inflorescence and number of seeds per capsule. Fifty inflorescences of both LPs and SPs were used in this study.

\section{Development of seed by cross-pollination}

Reciprocal crosses were made between LPs and SPs. The cross-pollinated flowers were covered with a piece of mosquito-net and marked with a tag. After 18 days, the mature capsules were collected and sun-dried. Number of capsules per inflorescence, number of seed-bearing capsules per inflorescence and number of seeds per capsule were recorded as described before. Eighteen inflorescences of both forms (LPs and SPs) were included in this study.

\section{Measurment of seeds}

Naturally pollinated, artificial self and crosspollinated seeds of both LPs and SPs were measured with the help of an Ocular micrometer (x 80).

\section{Results and Discussion}

Comparative study of pollen grains of both long petioled form (LPs) and short petioled form (SPs) of water hyacinth revealed signif- icant differences in the size of both oval and round pollen grains which are presented in Tables Ib and Ic.

\section{Comparative study of pollen grains of LPs and SPs}

The pollen grains were oval and round (Figs. 1a to d) in both LPs and SPs. Round pollen grains were found to be less in number in

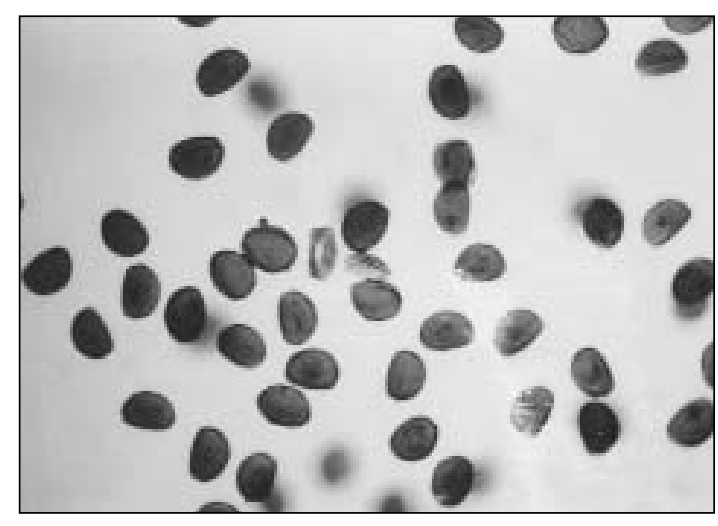

Fig. 1a.Photomicrographs showing the oval pollen grains of LPs $x 165$.

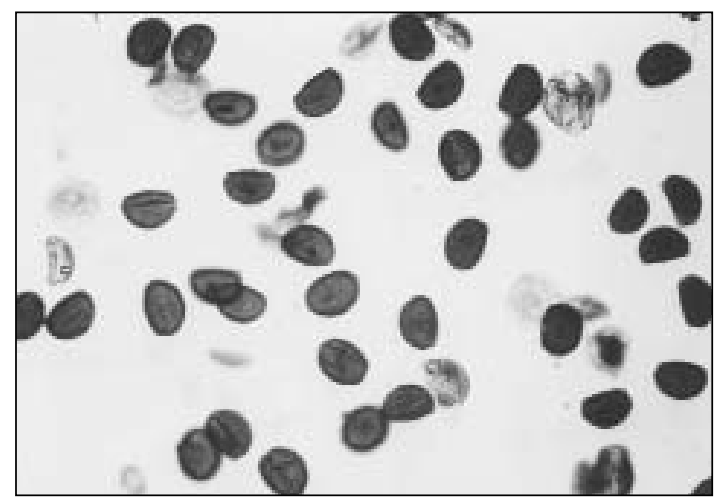

Fig. 1b. Photomicrographs showing the oval pollen grains of SPs x 165 . 


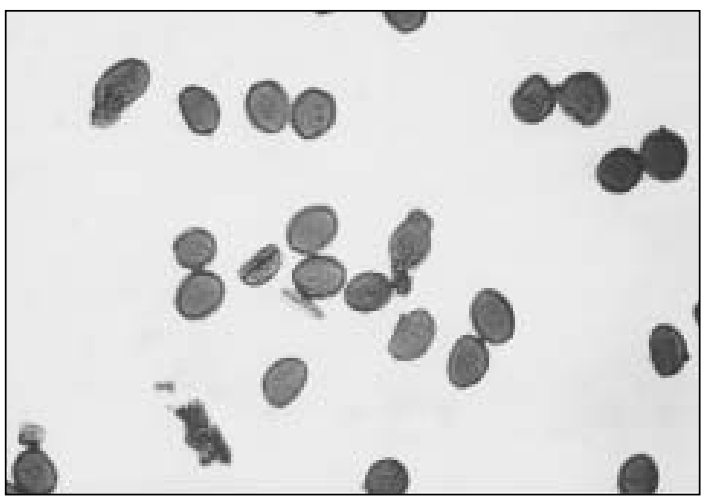

Fig. 1C. Photomicrographs showing the round and oval pollen grains of LPs $x$ 165.

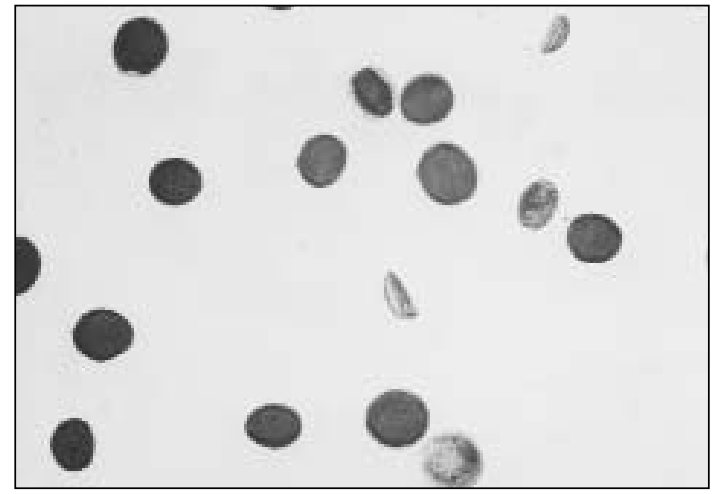

Fig. 1d. Photomicrographs showing the round and oval pollen grains of SPs x 165. comparison to the oval ones in both the forms. The stainability was also found to be more or less same, in that out of 1500 pollen grains studied, $91.2 \%$ in SPs and $91.3 \%$ in LPs were found to be stained (Table Ia).

Measurement of size of the oval and round pollen grains : The average length and breadth of oval pollen grains were more in SPs than LPs. The differences were significant at $5 \%$ and $1 \%$ level respectively (Table Ib). The average dia. of round pollen grains was more in SPs in comparison to LPs. The differences were significant at $1 \%$ level (Table Ic).

Pollen stainability was found to be more or less similar in LPs and SPs, but the size of both oval and round pollen grains was bigger in SPs in comparison to the LPs, the differences being statistically significant (Tables Ib and Ic).

The average length $(88.6 \pm 3.8 \mu)$ of pollen grains reported by Barrett was found to be greater but average breadth $(30.3 \pm 2.1 \mu)$ of pollen grains was found to be smaller than LPs and SPs of the present study (Table Ib). ${ }^{8}$

Table I. Pollen characteristics of LPs and SPs

Table Ia. Pollen stainability of two forms of water hyacinth LPs and SPs

\begin{tabular}{c|c|c|c|c|c}
\hline Form & $\begin{array}{c}\text { Total no. of } \\
\text { pollens studied }\end{array}$ & $\begin{array}{c}\text { Total no. of } \\
\text { stained pollens }\end{array}$ & $\begin{array}{c}\text { Total no. of non } \\
\text { stained pollens }\end{array}$ & $\begin{array}{c}\text { Percentage of } \\
\text { stained pollens }\end{array}$ & $\begin{array}{c}\text { Percentage of non } \\
\text { stained pollens }\end{array}$ \\
\hline LPs & 1500 & 1370 & 130 & 91.3 & 8.7 \\
SPs & 1500 & 1368 & 132 & 91.2 & 8.8 \\
\hline
\end{tabular}


Table Ib. Size of oval pollen grains

\begin{tabular}{c|c|c|c|c|c|c}
\hline \multirow{2}{*}{ Form } & \multicolumn{2}{|c|}{$\begin{array}{c}\text { Size of oval pollen grains } \\
(\mu \mathrm{m})\end{array}$} & $\begin{array}{c}\text { Mean of } \\
\text { length }\end{array}$ & $\begin{array}{c}\text { Mean of } \\
\text { breadth }\end{array}$ & $\begin{array}{c}\text { obs 't' value for } \\
\text { length }\end{array}$ & $\begin{array}{c}\text { obs 't' value for } \\
\text { breadth }\end{array}$ \\
\cline { 2 - 4 } & Length & Breadth & & & \\
\hline LPs & $40.0-85.0$ & $37.0-73.0$ & $65.27 \pm 2.65$ & $50.16 \pm 2.34$ & $2.43^{*}$ & $4.55^{* *}$ \\
SPs & $48.0-96.0$ & $31.85-88.50$ & $75.22 \pm 2.84$ & $66.78 \pm 2.80$ & 2.05 & \\
\hline
\end{tabular}

Table Ic. Size of round pollen grains.

\begin{tabular}{c|c|c|c}
\hline Form & $\begin{array}{c}\text { Diameter of round } \\
\text { pollen grains }(\mu \mathrm{m})\end{array}$ & Mean & observed t value \\
\hline LPs & $40.0-65.0$ & $57.49 \pm 1.31$ & $4.09 * *$ \\
SPs & $52.0-77.4$ & $66.86 \pm 1.88$ & \\
\hline
\end{tabular}

\section{Development of seed of LPs and SPs}

In case of comparative study of development of seed by natural and artificial self and cross-pollinated plants in both LPs and SPs, statistically significant differences in number of capsule and seeds/capsules are presented in Tables IIIa, IIIb and IIIc. In comparative study of measurements of seeds in artificially self and cross-pollinated plants of LPs and SPs, both length and breadth of seeds in selfpollinated plants were found to be significant and in cross-pollinated plants difference was observed only in length of the seeds, the results are presented in Tables IVb and c.

\section{Seed developed by natural pollination}

Blooming flowers were found to be visited by different types of insects (Preying mentid, Grassopher, Diptera etc). Over 500 flowers of LPs and SPs had been observed out of 100 naturally pollinated inflorescences of each form. The average number of capsules was found to be $15.70 \pm 0.77$ in LPs and $5.70 \pm$ 0.44 in SPs (Table IIIa). The average number of seed-bearing capsules was $2.05 \pm 0.64$ in LPs and $1.50 \pm 0.21$ in SPs. Some capsules were found to be empty which were also counted (Table IIa). The average number of seeds per capsule was also found to vary in both the forms. In LPs the average number of seeds was $34.50 \pm 5.96$ while that in SPs was $12.75 \pm 2.19$ (Table IIIa)

Significant differences were observed between LPs and SPs at $1 \%$ level in respect of their average number of capsules and seeds. The difference between the average number of seed- bearing capsules was found to be statistically insignificant (Table IIIa). 
Use of bagging method for development of artificial self and cross- pollinated seeds in LPs and SPs

Development of seeds in artificially self-pollinated flowers

In LPs and SPs 648 and 334 flowers were self-pollinated respectively by hand (Figs. 2a and $2 b$ ). These flowers were selected from 50

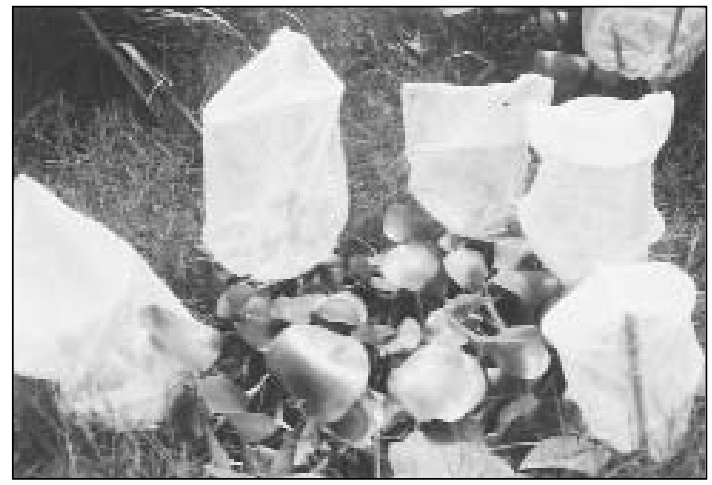

Fig. 2a. Flowers of SPs, cover by mosquitonet, supported by stick for artificial self and cross-pollination.

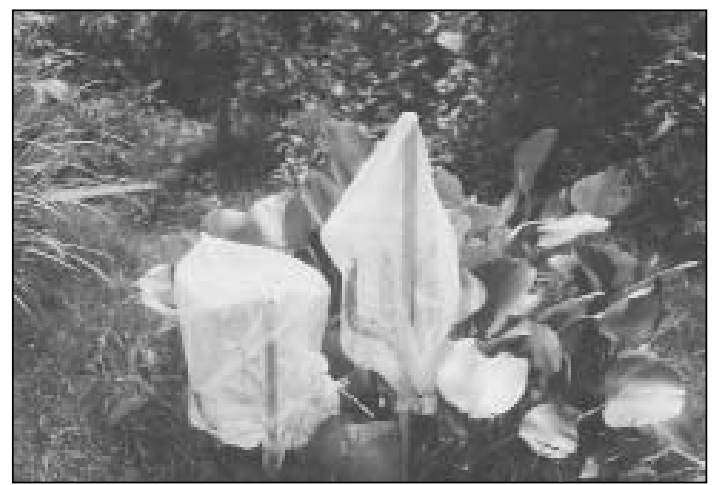

Fig. 2b. Flowers of LPs, covered by mosquitonet, supported by stick for artificial self and cross-pollination. inflorescences. The average number of capsules, seed-bearing capsules and number of seeds per capsule were counted. The results are shown in Table IIIb and compared with those, developing under natural conditions (Table IIIa). Number of empty capsules were also counted (Table IIb). In artificially self-pollinated flowers, the average number of capsules was found to be $13.80 \pm 1.10$ in LPs and $6.50 \pm 0.44$ in SPs. The average number of seed-bearing capsules was $11.40 \pm$ 1.44 in LPs and $5.70 \pm 1.41$ in SPs. The average number of seeds per capsule was found to be $158.72 \pm 13.94$ in LPs and $86.65 \pm$ 8.15 in SPs.

Significant differences were observed between LPs and SPs at $1 \%$ level in respect of their average number of capsules, seedbearing capsules and also number of seeds per capsule (Table IIIb).

Development of seeds in artificially cross-pollinated flowers.

Two hundred and twenty five flowers of LPs and 113 flowers of SPs were cross-pollinated by hand (Figs. 2a and 2b). These flowers were selected from 18 inflorescences. The results are shown in Tables IIc and IIIc and compared with those developing under natural conditions (Tables IIa and IIIa) and also with those self-pollinated by hand (Tables IIb and IIIb).

In artificially cross-pollinated flowers, the average number of capsules was found to be 
$12.94 \pm 0.64$ in LPs and $6.28 \pm 0.40$ in SPs. The average number of seed-bearing capsules was $11.67 \pm 0.09$ in LPs and $5.94 \pm$ 0.50 in SPs; the average number of seeds per capsule was $107.92 \pm 10.26$ in LPs and 71.52 \pm 6.60 in SPs. The differences observed between LPs and SPs in respect of their average number of capsules, seed-bearing capsules and also seeds per capsule were statistically significant at $1 \%$ level (Table IIIc). with artificially self and cross-pollinated plants of both LPs and SPs (Tables IIa to c).

The number of seed-bearing and empty capsules is shown in Table II.

\section{Measurements of seeds in LPs and SPs}

After counting the number of seeds (Figs. 3a to $f)$ per capsule, the size of the seeds was

Table II. Number of seeds-bearing and empty capsules in LPs and SPs.

\section{a : Naturally pollinated plants}

\begin{tabular}{c|c|c|c|c|c}
\hline Form & $\begin{array}{c}\text { Total no. of } \\
\text { flowers (100 inf.) }\end{array}$ & $\begin{array}{c}\text { Total no. of seed- } \\
\text { bearing capsules }\end{array}$ & $\begin{array}{c}\text { Total no. of empty } \\
\text { capsules }\end{array}$ & $\begin{array}{c}\text { \% of seed- bearing } \\
\text { capsules or seed set }\end{array}$ & $\begin{array}{c}\text { \% of empty } \\
\text { capsules }\end{array}$ \\
\hline LPs & 1533 & 43 & 1490 & 2.80 & 97.20 \\
SPs & 588 & 35 & 553 & 5.95 & 94.05 \\
\hline
\end{tabular}

Table IIb. Artificially self-pollinated plants

\begin{tabular}{c|c|c|c|c|c}
\hline Form & $\begin{array}{c}\text { Total no. of } \\
\text { flowers (50 inf.) }\end{array}$ & $\begin{array}{c}\text { Total no. of seed- } \\
\text { bearing capsules }\end{array}$ & $\begin{array}{c}\text { Total no. of empty } \\
\text { capsules }\end{array}$ & $\begin{array}{c}\text { \% of seed- bearing } \\
\text { capsules or seed set }\end{array}$ & $\begin{array}{c}\text { \% of empty } \\
\text { capsules }\end{array}$ \\
\hline LPs & 648 & 567 & 81 & 87.50 & 12.50 \\
SPs & 334 & 293 & 41 & 87.72 & 2.28 \\
\hline
\end{tabular}

Table IIc. Artificially cross-pollinated plants

\begin{tabular}{c|c|c|c|c|c}
\hline Form & $\begin{array}{c}\text { Total no. of } \\
\text { flowers (18 inf.) }\end{array}$ & $\begin{array}{c}\text { Total no. of seed- } \\
\text { bearing capsules }\end{array}$ & $\begin{array}{c}\text { Total no. of empty } \\
\text { capsules }\end{array}$ & $\begin{array}{c}\text { \% of seed- bearing } \\
\text { capsules or seed set }\end{array}$ & $\begin{array}{c}\text { \% of empty } \\
\text { capsules }\end{array}$ \\
\hline LPs & 225 & 211 & 14 & 93.78 & 6.22 \\
SPs & 113 & 107 & 6 & 94.69 & 5.31 \\
\hline
\end{tabular}

The number of empty capsules was found to be more in naturally pollinated plants in comparison with the artificially self and crosspollinated plants (Tables IIa to c) of both LPs and SPs. It was also observed that number of seed-bearing capsules was found to be less in naturally pollinated plants in comparison measured with the help of an Ocular micrometer (Table IV).

\section{Measurements of seeds in naturally pollinated} plants

The study yielded statistically insignificant results (Table IVa). 


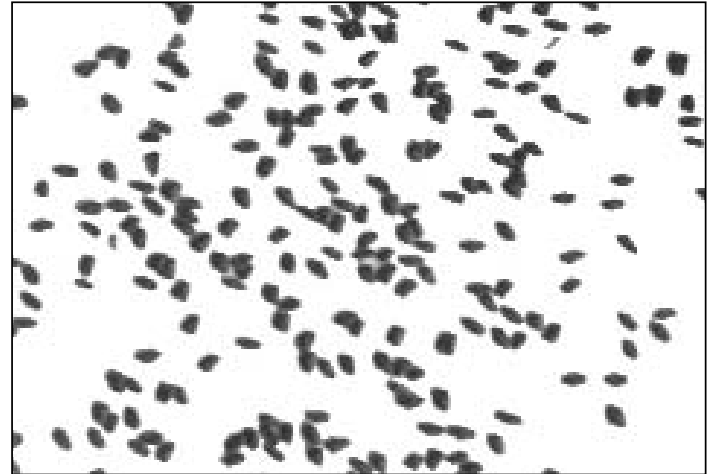

Fig. 3a. Seeds of naturally pollinated LPs $x$ 246.

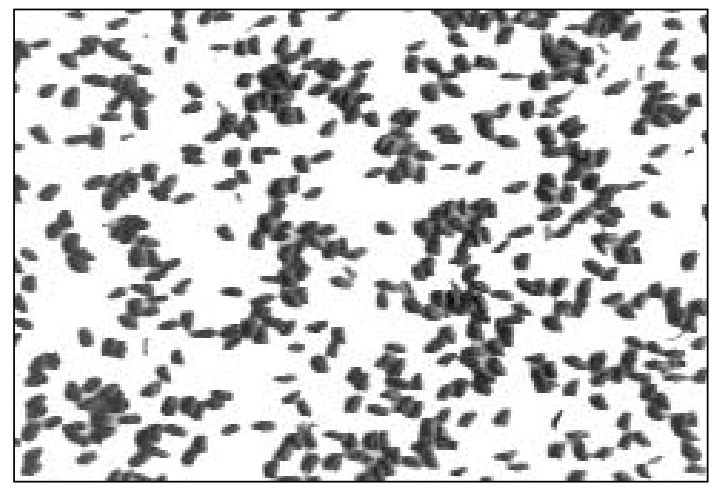

Fig. 3c. Seeds of artificially self-pollinated LPs x 246.

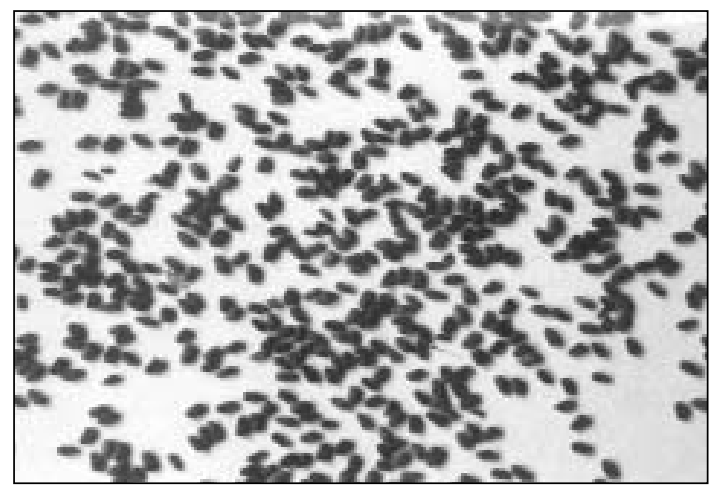

Fig. 3e. Seeds of artificially cross-pollinated LPs x 246.

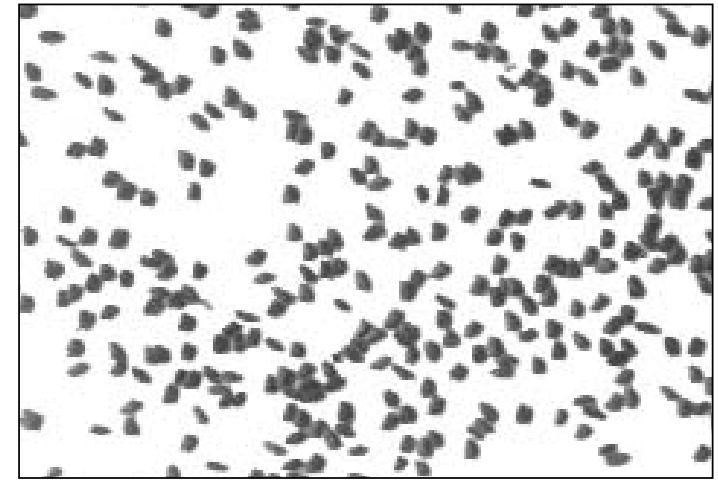

Fig. 3b. Seeds of naturally pollinated SPs $x$ 246.

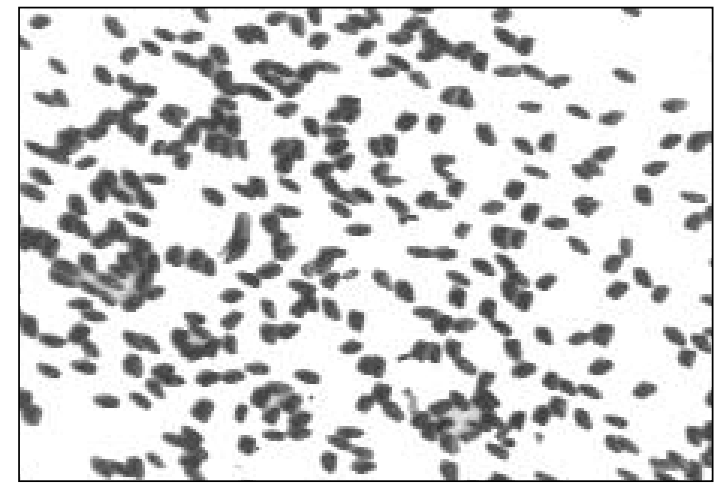

Fig. 3d. Seeds of artificially self-pollinated SPs x 246.

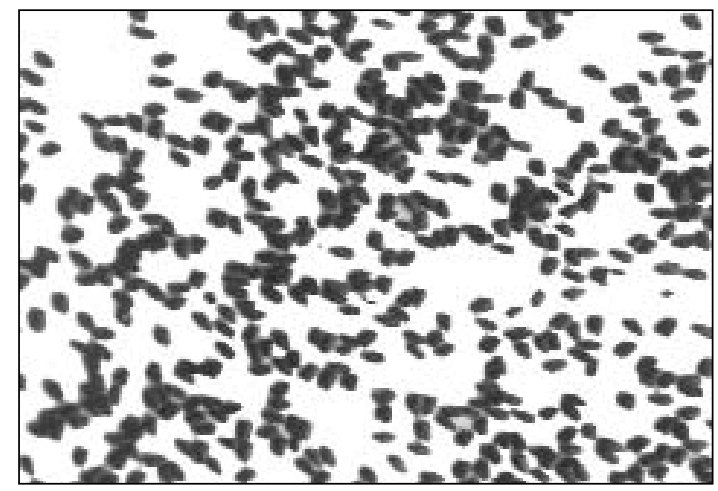

Fig. 3f. Seeds of artificially cross-pollinated SPs x 246. 
Table III. Number of capsules and seeds/capsule in LPs and SPs a : Naturally pollinated plants

\begin{tabular}{l|c|c|c|c|c|c|c}
\hline Form & $\begin{array}{c}\text { Mean of } \\
\text { capsules }\end{array}$ & $\begin{array}{c}\text { Mean of seed- } \\
\text { bearing capsule }\end{array}$ & $\begin{array}{c}\text { Total no. } \\
\text { of seeds }\end{array}$ & $\begin{array}{c}\text { Mean of } \\
\text { seeds/ capsule }\end{array}$ & $\begin{array}{c}\text { 't' value } \\
\text { for capsule }\end{array}$ & $\begin{array}{c}\text { 't' value for } \\
\text { seed-bearing } \\
\text { capsule }\end{array}$ & $\begin{array}{c}\text { 't' value for } \\
\text { seeds/ capsule }\end{array}$ \\
\hline LPs & $15.70 \pm 0.77$ & $2.05 \pm 0.64$ & 885 & $34.50 \pm 5.96$ & $11.17^{* *}$ & 0.80 & $3.42^{* *}$ \\
SPs & $5.70 \pm 0.44$ & $1.50 \pm 0.21$ & 334 & $12.75 \pm 2.19$ & & & \\
\hline
\end{tabular}

Table IIIb. Artificially self-pollinated plants

\begin{tabular}{l|c|c|c|c|c|c|c}
\hline Form & $\begin{array}{c}\text { Mean of } \\
\text { capsules }\end{array}$ & $\begin{array}{c}\text { Mean of seed- } \\
\text { bearing capsule }\end{array}$ & $\begin{array}{c}\text { Total no. } \\
\text { of seeds }\end{array}$ & $\begin{array}{c}\text { Mean of } \\
\text { seeds/ capsule }\end{array}$ & $\begin{array}{c}\text { 't' value } \\
\text { for capsule }\end{array}$ & $\begin{array}{c}\text { 't' value for } \\
\text { seed-bearing } \\
\text { capsule }\end{array}$ & $\begin{array}{c}\text { 't' value for } \\
\text { seeds/ capsule }\end{array}$ \\
\hline LPs & $13.80 \pm 1.10$ & $11.40 \pm 1.44$ & 47455 & $158.72 \pm 13.94$ & $6.16^{* *}$ & $2.81^{* *}$ & $4.46^{* *}$ \\
SPs & $6.50 \pm 0.44$ & $5.70 \pm 1.41$ & 15209 & $86.65 \pm 8.15$ & & & \\
\hline
\end{tabular}

Table IIIc. Artificially cross-pollinated plants

\begin{tabular}{c|c|c|c|c|c|c|c}
\hline Form & $\begin{array}{c}\text { Mean of } \\
\text { capsules }\end{array}$ & $\begin{array}{c}\text { Mean of seed- } \\
\text { bearing capsule }\end{array}$ & $\begin{array}{c}\text { Total no. } \\
\text { of seeds }\end{array}$ & $\begin{array}{c}\text { Mean of } \\
\text { seeds/ capsule }\end{array}$ & $\begin{array}{c}\text { 't' value } \\
\text { for capsule }\end{array}$ & $\begin{array}{c}\text { 't' value for } \\
\text { seed-bearing } \\
\text { capsule }\end{array}$ & $\begin{array}{c}\text { 't' value for } \\
\text { seeds/ capsule }\end{array}$ \\
\hline LPs & $12.44 \pm 0.64$ & $11.67 \pm 0.09$ & 18214 & $107.92 \pm 10.26$ & $8.03^{* *}$ & $5.70^{* *}$ & $2.70^{* *}$ \\
\hline SPs & $6.28 \pm 0.40$ & $5.94 \pm 0.50$ & 7297 & $71.52 \pm 6.60$ & & \\
\hline
\end{tabular}

** and * represents significant at $1 \%$ level and $5 \%$ level respectively.

Measurements of seeds in artificially self-pollinated plants

The study yielded statistically significant results (Table IVb).

Measurements of seeds in artificially cross-pollinated plants

The differences between LPs and SPs in respect of their average length of seeds were found to be significant at $1 \%$ level while the average breadth of seeds was found to be statistically insignificant (Table IVc).
All statistical analysis was followed as per method of Islam. $^{9}$

Ridley observed that water hyacinth plant reproduces only vegetatively in its adventive range. ${ }^{10}$ Bock reported the absence of sexual reproduction in California. ${ }^{6}$ Penfound and Earle observed mature fruits from May to December. ${ }^{11}$ Mitchell and Thomas did not find seeds or mature fruits in any areas of South America. ${ }^{12}$ Bruhl and Sengupta obtained seeds by artificial pollination. ${ }^{13}$ Agharkar and Banerjee reported that bagging the flowers produced fruits indicating that 
Table IV. Comparative measurement of seeds of LPs and SPs a : In naturally pollinated plants

\begin{tabular}{c|c|c|c|c|c|c}
\hline \multirow{2}{*}{ Form } & $\begin{array}{c}\text { Size of naturally pollinated } \\
\text { seeds }(\mathrm{mm})\end{array}$ & $\begin{array}{c}\text { Mean of } \\
\text { seed length }\end{array}$ & $\begin{array}{c}\text { Mean of seed } \\
\text { breadth }\end{array}$ & $\begin{array}{c}\text { 't' value for } \\
\text { length }\end{array}$ & $\begin{array}{c}\text { 't' value for } \\
\text { breadth }\end{array}$ \\
\cline { 2 - 5 } & Length & Breadth & & $0.55 \pm 0.02$ & 0.39 & 0.75 \\
\hline LPs & $1.08-1.43$ & $0.48-0.67$ & $1.24 \pm 0.03$ & 0.55 . \\
SPs & $1.08-1.35$ & $0.05-0.63$ & $1.23 \pm 0.02$ & $0.56 \pm 0.01$ & \\
\hline
\end{tabular}

Table IVb. In artificially self-pollinated plants

\begin{tabular}{|c|c|c|c|c|c|c|}
\hline \multirow[t]{2}{*}{ Form } & \multicolumn{2}{|c|}{$\begin{array}{c}\text { Size of naturally pollinated } \\
\text { seeds (mm) }\end{array}$} & \multirow[t]{2}{*}{$\begin{array}{c}\text { Mean of } \\
\text { seed length }\end{array}$} & \multirow[t]{2}{*}{$\begin{array}{c}\text { Mean of seed } \\
\text { breadth }\end{array}$} & \multirow[t]{2}{*}{$\begin{array}{l}\text { 't' value for } \\
\text { length }\end{array}$} & \multirow[t]{2}{*}{$\begin{array}{l}\text { 't' value for } \\
\text { breadth }\end{array}$} \\
\hline & Length & Breadth & & & & \\
\hline LPs & $1.15-1.50$ & $0.57-0.73$ & $1.36 \pm 0.04$ & $0.65 \pm 0.01$ & \multirow{2}{*}{$2.14^{*}$} & \multirow{2}{*}{$2.70 *$} \\
\hline SPs & $1.08-1.43$ & $0.47-0.72$ & $1.27 \pm 0.02$ & $0.60 \pm 0.021$ & & \\
\hline
\end{tabular}

Table IVc. In artificially cross-pollinated plants

\begin{tabular}{c|c|c|c|c|c|c}
\hline \multirow{2}{*}{ Form } & $\begin{array}{c}\text { Size of naturally pollinated } \\
\text { seeds }(\mathrm{mm})\end{array}$ & $\begin{array}{c}\text { Mean of } \\
\text { seed length }\end{array}$ & $\begin{array}{c}\text { Mean of seed } \\
\text { breadth }\end{array}$ & $\begin{array}{c}\text { 't' value for } \\
\text { length }\end{array}$ & $\begin{array}{c}\text { 't' value for } \\
\text { breadth }\end{array}$ \\
\cline { 2 - 5 } & Length & Breadth & & & \\
\hline LPs & $1.17-1.58$ & $0.53-0.72$ & $1.35 \pm 0.03$ & $0.64 \pm 0.01$ & $1.72^{*}$ & $1.56^{*}$ \\
SPs & $1.18-1.40$ & $0.49-0.73$ & $1.30 \pm 0.01$ & $0.61 \pm 0.01$ & \\
\hline
\end{tabular}

** and * represents significance at $1 \%$ level and $5 \%$ level respectively.

self-pollination occurs to a considerable extent. $^{7}$ Agarkar and Banerjee (L.c.) also noted that pollination was not always followed by fruit formation because of interference by other factors (temperature and humidity). In general Aghakar and Banerjee (L.c.) reported that seed formation took place in submerged flowers. Subramanyam also mentioned that seed formation took place only in submerged inflorescence. ${ }^{14}$ Das observed that submergence was not necessary for seed formation. ${ }^{15}$ The present study agrees with the observation of Das (L.c.). The confirmation was obtained when seed-bearing capsules resulted from artificial pollination of flowers, supported above water level by means of net ( Figs. 2a and 2b). Tag El Seed and Obeid reported that in water hyacinth in artificially self-pollinated plants, most of the flowers formed capsules containing seeds. ${ }^{3}$ The present findings are in confirmity with Tag E1 Seed and Obeid's findings 
as most of artificially pollinated flowers produced seed bearing capsules. ${ }^{3}$ Agharkar and Banerjee in India, reported that about $35 \%$ of the flowers were successfully naturally pollinated. ${ }^{7}$ Haigh reported that in Srilanka $29 \%$ of the flowers bore capsules and Mclean observed $1 \%$ of the flowers in Bengal setting seeds, while according to Backer fruits were unknown in Malaysia and Java. ${ }^{16,17,5}$ In the present study, only $2.80 \%$ of the flowers were naturally pollinated in LPs and $5.95 \%$ in SPs.

Barrett reported that seed production in artificial and naturally pollinated flowers was found to be higher in mid-styled than in longstyled form. ${ }^{18}$ In the present study, longstyled form was totally absent and only midstyled form was found to produce seeds. The number of seeds were found to be higher in artificially self and cross-pollinated plants in comparison to the naturally pollinated plants (Tables IIIa to c).

Barrett reported that out of 2,546 flowers $94.7 \%$ produced capsules with an average of 143.3 seeds per capsules. ${ }^{19}$ Barrett (L.c.) also reported that no significant differences in seed set had been observed between self and cross-pollinated plants of Louisiana, Florida, Mexico and Southern Brazil.

In the present study, significant differences were observed in seed set between self and cross-pollinated plants of both LPs and SPs (Table IIIb and IIIc).
Barrett reported that seed set was significantly higher in cross-pollinated plants in comparison to self-pollinated plants in California, Sudan and Calcutta. ${ }^{20}$ The findings of Barrett (L.c.) are in agreement with the present study (Tables IIa to c).

The number of fruits or capsules per plant also varies greatly. Dekimpe observed only four capsules out of 139 inflorescences; Das observed 11 capsules out of five inflorescences.. ${ }^{21,2}$ Tag El Seed and Obeid reported zero to 16 (average $1.5 \pm 2.3$ ) capsules per inflorescence and some workers observed five capsules per inflorescence. ${ }^{3}$

In the present study, out of 100 naturally pollinated inflorescence, 1 to 14 capsules per inflorescence in LPs and 1 to 4 capsules per inflorescence in SPs were observed (Table IIIa). In self-pollinated plants, out of 50 inflorescence 1 to 25 capsules per inflorescence in LPs and 1 to 10 capsules per inflorescence in SPs were observed (Table IIIb). In cross-pollinated plants, out of 18 inflorescence 2 to 17 capsules per inflorescence in LPs and 1 to 9 capsules per inflorescence in SPs were observed (Table IIIc).

It was also observed that the number of seeds per capsule was found to be remarkably variable. Dekimpe reported three to 364 seeds per capsule; Gopal and Sharma reported two 160 seeds per capsule; Penfound and Earle, Robertson and Thein reported 50 to 60 seeds per capsule; Muller observed more than 260 seeds per capsule; Tag El Seed and Obeid 
recorded five to 452 seeds per capsule; Francois obtained upto 390 seeds per capsule, while Reddy and Bahadur obtained a maximum of 67 seeds per capsule. ${ }^{21,22,11,23,24,3,25,26}$

In the present study, in naturally pollinated plants one to 108 seeds per capsule in LPs and one to 45 seeds per capsule in SPs were observed. In self-pollinated plants, one to 273 seeds per capsule in LPs and one to 226 seeds per capsule in SPs were observed. In cross-pollinated plants, two to 206 seeds per capsule in LPs and three to 148 seeds per capsule in SPs were observed. The number of seeds per capsule was found to be higher in self-pollinated plants than in cross-pollinated plants in both forms.

Oki and Ueki reported that the emerged plants produced more inflorescence and seeds than floating plants. ${ }^{27}$ The present study agrees with this observation.

In the present study it was found that some capsules contained seeds while others did not. The percentage of seed-bearing capsules was found to be higher in artificially self and cross-pollinated plants in comparison with naturally pollinated plants (Tables IIa to c). On the other hand, the number and percentage of empty capsules were found to be higher in naturally pollinated plants in comparison with the artificially self and cross-pollinated plants (Tables IIa to c). From the above observation it may be concluded that both artificial self and cross-pollinations produce greater number of seed-bearing capsules with a higher number of seeds per capsule in both forms. It may be mentioned here that no other report has been observed on the existence of empty capsules.

\section{Conclusion}

From the comparative study of pollen grain and development of seeds in both long petioled (LPs) and short petioled (SPs) form of water hyacinth it is evident that water hyacinth has two different forms.

\section{Acknowledgement}

Sincere thanks are due to BCSIR authority for giving facilities during the study. Thanks are also due to Late Professor Salar Khan, Department of Botany, University of Dhaka for his suggestion and kind help during the study.

\section{References}

1. S. C. H. Barrett. Water Weed invasions. Scientific American 260(10) (1989) 90-97.

2. R. R. Das. A study of reproduction in Eichhornia crassipes (Mart.) Solms. Trop. Ecol. 10 (1969) 195-198.

3. M. S. TagEl and M. Obeid. Sexual reproduction of Eichhornia crassipes (Mart.) Solms in the Nile. Weed Research 15 (1975) 7-12. 
4. F. Myers. Hyacinth control. 10th biennial Rept. Louisiana wild life and fish. Comm. 63 (1964) 61-67.

5. C. A. Backer. Pontederiaceae. In : Van steenin (Ed), Flora Malesiana, Ser 1(4) (1951) 259-261.

6. J. H. Bock. An ecological study of Eichhornia crassipes (Mart.) Solms with special emphasis on its reproductive biology. Ph.D. dissertation, Univ. of California, Berkely (1966).

7. S. P. Agharkar and I. Banerjee. Studies in the pollination and seed formation of water hyacinth (Eichhornia speciosa kunth) Agric. J. India, 35 (1930) 286-296.

8. S. C. H. Barrett. Tristyly in Eichhornia crassipes (Mart.) Solms (Water hyacinth). Biotropica 9(4) (1977) 230-238.

9. A. S. Islam. Fundamentals of Genetics (in Bengali), Bangla Academy, Dhaka Bangladesh (1984).

10. H. N. Ridley. The dispersal of plants throughout the world. L. Reeve, London. (1930) 177-231.

11. W. T. Penfound and T. T. Earle. The biology of water hyacinth. Ecol. Monogr. 18 (1948) 447-472.

12. D. S. Mitchell and P. A. Thomas. Ecology of water weeds in the Neotropics- an ecological survey of the aquatic weeds, Eichhornia crassipes and Salvinia species, and their natural enemies in the neotropics. UNESCO, Paris, Tech.Pap. Hydrology, 12 (1972) 50.

13. P. Bruhl and J. Sengupta. On the production of ripe seeds by artificial pollination of Eichhornia speciosa, J. Dept. Sci. Univ. of Calcutta. 8 (1927) 1-8.

14. K. Subramanyam. Aquatic angios-perms, CSIR, New Delhi, (1961) 70-72.

15. R. R. Das. Growth and distribution of Eichhornia crassips and Spirodela polyrhiza. Ph. D. Thesis, Banaras Hindu Univ., Varanasi, India (1968).

16. J. C. Haigh. Notes on the water hyacinth Eichhornia crassipes (Mart.) Solms in Ceylon. Cey. J. Sci. 12 (1936) 97-107.

17. K. Mclean. Water hyacinth. A serious pest in Bengal. Agric J. India 17 (1922) 23-40.

18. S. C. H. Barrett. The evolutionary breakdown of tristyle in Eichhornia crassipes (Mart.) Solms (water hyacinth). Evolution 33(1) (1979) 499-510.

19. S. C. H. Barrett. Breeding system in Eichhornia and Pontederia, tristylous genera of the Pontederiaceae. Ph. D. dissertation, Univ. of California, Berkeley, (1977).

20. S. C. H. Barrett. Sexual reproduction in Eichhornia crassipes (water hyacinth) II. Seed production in natural populations. J.Appl. Ecol. 17 (1980) 113-124. 
21. P. Dekimpe. Controlle dela jacinthe d'equ. Bull. Agric. du Congo Belge 48 (1957) 105-152.

22. B. Gopal and K. P. Sharma. Water hyacinth (Eichhornia crassipes), most troublesome weed of the world. Hindasia, New Delhi., (1981) 37-45.

23. H. F. Robertson and B. A. Thein. The occurrence of water hyacinth (Eichhor-nia crassips) seedlings under natural conditions in Burma. Agric. and livestock of India 2 (1932) 383-390.

24. Muller, F. Einige Eigentumlichkei-ten der Eichhornia crassipes. Kosmos 13 (1883) 297-300.
25. J. Francois. Observations Sur I' heterostylie chez Eichhornia crassipes (Mart.) Solms. Bull. Acad. Roy sci.d' outer Mer seances, (1964) 501-519.

26. N. P. Reddy and Bir Bahadur. Heterostyly in Eichhornia crassipes (Mart.) Solms. J. Indian Bot. Soc. 56(4) (1977) 299-307.

27. Y. Oki and K. Ueki. Adaptation of water hyacinth grown under various habitats. Proceedings of the international conference on water hyacinth, UNEP, Nairobi,. (1984) 222-232. 